\title{
CARACTERIZAÇÃO FÍSICA E FÍSICO-QUÍMICA EM FRUTOS DE MURICI (Byrsonima crassifolia (L.) Rich.) DE OCORRÊNCIA NOS TABULEIROS COSTEIROS DE ALAGOAS
}

\author{
Everton Ferreira dos Santos ${ }^{1}$, José Dailson Silva de Oliveira ${ }^{2}$, Ivanildo Claudino da Silva ${ }^{3}$, Cibele Merched \\ Gallo ${ }^{4}$, Eurico Eduardo Pinto de Lemos ${ }^{5}$, Leila de Paula Rezende ${ }^{6}$
}

\begin{abstract}
'Engenheiro Agrônomo, Mestre em Agronomia, Centro de Ciências Agrárias (CECA), Universidade Federal de Alagoas (UFAL), BR 104 Norte, Km 85, Rio Largo, AL. CEP 57.000-100.

2Engenheiro Agrônomo, Doutorando em Agronomia, Centro de Ciências Agrárias (CECA), Universidade Federal de Alagoas (UFAL), BR 104 Norte, Km 85, Rio Largo, AL. CEP 57.000-100.

${ }^{3}$ Engenheiro Agrônomo, Mestre em Agronomia, Centro de Ciências Agrárias (CECA), Universidade Federal de Alagoas (UFAL), BR 104 Norte, Km 85, Rio Largo, AL. CEP 57.000-100.

${ }^{4}$ Bióloga, Doutora em Agronomia, Bolsista PDCR - Fruticultura, Centro de Ciências Agrárias (CECA), Universidade Federal de Alagoas (UFAL), BR 104 Norte, Km 85, Rio Largo, AL. CEP 57.000-100.

${ }^{5}$ Professor, Doutor em Biotecnologia, Centro de Ciências Agrárias (CECA), Universidade Federal de Alagoas (UFAL), BR 104 Norte, Km 85, Rio Largo, AL. CEP 57.000-100.

${ }^{6}$ Professora, Doutora em Fitotecnia, Centro de Ciências Agrárias (CECA), Universidade Federal de Alagoas (UFAL), BR 104 Norte, Km 85, Rio Largo, AL. CEP 57.000-100.
\end{abstract}

Autor para correspondência: Everton Ferreira dos Santos, everton_federal@hotmail.com

RESUMO: O muricizeiro nativo da flora alagoana é uma espécie frutífera com potencial de utilização em sistemas produtivos comerciais, no entanto, pouco se conhece acerca das características físicas e físico-químicas dos frutos. Desta forma, o objetivo foi avaliar as características físicas e físico-químicas de frutos de muricizeiro que ocorrem naturalmente nos tabuleiros costeiros alagoanos. Os caracteres físicos foram obtidos por meio de 50 medições, individualmente, consistindo em 50 frutos por parâmetro avaliado, em relação ao peso do fruto e da semente, diâmetro longitudinal e transversal do fruto, diâmetro da semente e textura. Os parâmetros físicoquímicos foram obtidos por meio de cinco repetições, para cada característica. Foi utilizado de 1 a $10 \mathrm{~g}$ de polpa do fruto, a depender da análise realizada. As características avaliadas foram: sólidos totais (ST), acidez total (AT), relação ST/AT, vitamina $C$, carotenoides, antocianinas, flavonoides, pectina total e solúvel. Foi aplicada estatística descritiva, obtendo-se os valores mínimos, médios e máximos, erro padrão da média e coeficiente de variação.

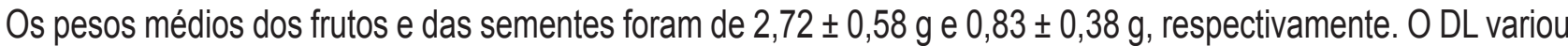
de $12,27 \mathrm{~mm}$ a $14,47 \mathrm{~mm}$, com DT oscilando de $15,27 \mathrm{~mm}$ a $18,12 \mathrm{~mm}$, e textura variando de $1,60 \mathrm{~N}$ a $4,76 \mathrm{~N}$. 0 diâmetro médio da semente foi $2,09 \pm 0,59 \mathrm{~mm}$ (milímetro). Com relação às caraterísticas físico-químicas, os frutos apresentaram altos teores de sólidos totais, vitamina $\mathrm{C}$ e compostos bioativos, indicando o potencial da espécie tanto para o consumo in natura quanto para o processamento.

PALAVRAS-CHAVE: fruteira nativa, biometria de frutos, qualidade pós-colheita, potencial de utilização.

\section{PHYSICAL AND PHYSICAL-CHEMICAL CHARACTERIZATION IN MURICI FRUITS (Byrsonima crassifolia (L.) Rich.) OCCURRENCE IN THE COASTAL BOARDS OF ALAGOAS}

\begin{abstract}
The native muricizeiro of the Alagoas flora is a fruit species with potential of use in commercial productive systems; however, little is known about the physical and physical-chemical characteristics of the fruits. In this way, the objective was to evaluate the physical and physicochemical characteristics of mulberry trees occurring naturally in the Alagoas coastal trays. The physical characters were obtained by means of 50 measurements, individually, consisting of 50 fruits per parameter evaluated, in relation to the weight of the fruit and the seed, longitudinal and transverse diameter of the fruit, seed diameter and texture. The physical-chemical parameters were obtained by means of five repetitions, for each characteristic. From 1 to $10 \mathrm{~g}$ of fruit pulp was used, depending on the analysis performed. The evaluated characteristics were: total solids (ST), total acidity
\end{abstract}


(AT), ST / AT ratio, vitamin C, carotenoids, anthocyanins, flavonoids, total pectin and soluble. Descriptive statistics were applied, obtaining the minimum, mean and maximum values, standard error of the mean and coefficient of variation. The mean fruit and seed weights were $2.72 \pm 0.58 \mathrm{~g}$ and $0.83 \pm 0.38 \mathrm{~g}$, respectively. The DL varied from $12.27 \mathrm{~mm}$ to $14.47 \mathrm{~mm}$, with DT ranging from $15.27 \mathrm{~mm}$ to $18.12 \mathrm{~mm}$, and texture ranging from $1.60 \mathrm{~N}$ to $4.76 \mathrm{~N}$. The mean diameter of the seed was 2,09 $\pm 0.59 \mathrm{~mm}$ (millimeter). Regarding the physical-chemical characteristics, the fruits presented high levels of total solids, vitamin $\mathrm{C}$ and bioactive compounds, indicating the potential of the species for both in nature consumption and processing.

KEYWORDS: native fruit, fruit biometry, post-harvest quality, potential for use.

\section{INTRODUÇÃO}

A flora de Alagoas possui diversas espécies frutíferas nativas não conhecidas ou pouco conhecidas, com potencial de utilização em sistemas produtivos comerciais, que são tradicionalmente utilizadas e consumidas pelas populações locais para os mais diversos fins. 0 conhecimento das frutas nativas para fins alimentares é bastante antigo, sendo repassado dos indígenas aos colonizadores, no entanto, atualmente essas plantas vêm sofrendo grande risco de extinção, devido à ampliação das áreas de cultivo e também pela exploração irracional nos ecossistemas em que ocorrem, sendo necessários estudos visando sua preservação, conservação e valorização no mercado competitivo de frutas (Centro Ecológico, Rede Ecovida de Agroecologia e Terra do Futuro [CETAP], 2015).

Dentre as espécies frutíferas nativas do Estado de Alagoas com alto potencial de uso atual e futuro, destaca-se o muricizeiro (Byrsonima spp.), espécie que ocorre naturalmente em áreas de tabuleiros costeiros e restingas arenosas de Alagoas, frutificando de dezembro a fevereiro, sendo muito apreciado como fonte de energia na alimentação e uso na medicina popular (Flora do Brasil, 2018; Araújo et al., 2009).

Pertencente à família Malpghiaceae, o muricizeiro ( $B$. crassifólia $L$. Rich) possui porte médio apresentado de 2 a 6 metros de altura, com folhas simples e coriáceas. Suas flores são amareladas, apresentando-se em racimos alongados terminais. 0 fruto é uma drupa pequena, apresenta um odor forte, semelhante a queijo rançoso, agridoce e ligeiramente oleoso, apresentando coloração verde quando imaturo, aonde vai adquirindo coloração amarelada no decorrer do amadurecimento até a senescência. É consumido tanto de forma in natura como processado na forma de sucos, licores, sorvetes, geleias, cremes, entre outras formas (Belisário et al., 2013).

Os estudos da biometria de frutos e sementes consistem numa importante ferramenta para 0 planejamento em relação à comercialização póscolheita de frutos, bem como para a preservação e exploração racional dos recursos naturais. Além disso, é um importante instrumento para caracterizar a variabilidade genética presente nas populações de uma mesma espécie, e a correlação existente entre determinada variabilidade e os fatores bióticos do meio, e dessa forma, gerando informações que possam ser utilizadas em programas de melhoramento genético (Blind et al., 2016; Zuffo et al., 2014; Araújo et al., 2009).

Ao se estudar a qualidade pós-colheita de frutos nativos, várias características podem ser analisadas, tais como: $\mathrm{pH}$, acidez total, sólidos totais, ácido ascórbico, pectina total, pectina solúvel, antocianinas, flavonoides e carotenoides. O conhecimento sobre as características físico-químicas, nutricionais e fitoquímicas são informações quantitativas e qualitativas importantes em frutos, pois induz ao interesse crescente da população pelo consumo e desenvolvimento de novos produtos, bem como oferece uma alternativa de atividade sustentável para as populações das regiões de ocorrência (Silva et al., 2015; Rocha et al., 2013; Canuto et al., 2010).

Tendo em vista a escassez de dados na literatura especializada com relação aos caracteres físicoquímicos em frutos nativos, e a crescente procura por alimentos com características nutricionais e funcionais que atenda o mercado consumidor, que está cada vez mais em busca de alimentos diferenciados. 0 objetivo deste trabalho foi avaliar as características físicas e físico-químicas de frutos de muricizeiro que ocorrem naturalmente nos tabuleiros costeiros alagoanos.

\section{MATERIAL E MÉTODOS}

\section{Local de execução e coleta do material vegetal}

0 estudo foi desenvolvido no Laboratório de Pós-colheita de Frutos do Centro de Ciências Agrárias da Universidade Federal de Alagoas (CECA/UFAL), 
localizado em Rio Largo - Alagoas (latitude $9^{\circ} 29^{\prime} 45^{\prime \prime}$ S, longitude $35^{\circ} 49^{\prime} 54^{\prime \prime} \mathrm{W}$, altitude de 127 metros). Os frutos utilizados na pesquisa foram coletados de matrizes de muricizeiro ( $B$. crassifólia $L$. Rich) presente no CECA/UFAL. O clima da região segundo Köppen é tropical chuvoso, com verão seco e precipitação média anual de 1.150,2 mm, sendo os meses mais secos de novembro a dezembro e os mais chuvosos entre julho e agosto (Secretaria de Estado do Meio Ambiente e dos Recursos Hídricos [SEMARH], 2015).

Foram coletados aproximadamente $1000 \mathrm{~g}$ de frutos, e acondicionados em caixa com isolamento térmico com gelo e transportados para o Laboratório de Pós-colheita de Frutos - CECA/UFAL. Os frutos foram lavados em água corrente, sanitizados em hipoclorito de sódio, na proporção de $5 \mathrm{~mL}$ de cloro para cada litro de água, e mantidos nesta solução por 30 minutos. Posteriormente foram enxaguados, para a remoção de resíduos de cloro aderidos na casca dos frutos. Em seguida foram desintegrados em multiprocessador, obtendo-se aproximadamente $700 \mathrm{~g}$ de polpa. As polpas dos frutos foram mantidas a $-10^{\circ} \mathrm{C}$ até o momento das análises.

\section{Caracterização física}

Acaracterizaçãofísica dosfrutosfoideterminada por meio da média de 50 frutos para as variáveis: peso do fruto, peso da semente, diâmetro longitudinal e transversal do fruto e da semente e firmeza do fruto. 0 diâmetro longitudinal (DL) e o diâmetro transversal (DT) dos frutos e sementes foram determinados com auxilio de paquímetro digital (6G-150 mm), com os resultados expressos em $\mathrm{mm}$. 0 peso do fruto e da semente foi realizado através de pesagem individual de cada fruto em balança digital de precisão centesimal 0,01g-Mark 1300 , sendo os resultados expressos em gramas $(\mathrm{g})$. A firmeza do fruto foi determinada com auxílio de um penetrômetro digital tipo PTR 300 , e os resultados expressos em Newtons (N).

\section{Caracterização físico-química}

Para as variáveis físico-químicas: ST ( $\left.{ }^{\circ} B r i x\right)$, AT, pH, ácido ascórbico, antocianinas, flavonoides, carotenoides, pectina total e pectina solúvel, foram obtidas médias de cinco amostras.

O teor de Sólidos Totais (ST) foi determinado com o auxílio de um refratômetro digital modelo
PDR 50B, com escala de variação de 0 a $65^{\circ}$ Brix e os resultados foram expressos em ${ }^{\circ}$ Brix, conforme a Association of Official Analytical Chemists International (AOAC, 1995). O potencial hidrogeniônico (pH), foi determinado diretamente nas amostras, em medidor digital de bancada mPA-210, segundo técnica da AOAC (1995).

A acidez total (expressa em \% de ácido cítrico), foi realizada por titulação com solução de hidróxido de sódio $(\mathrm{NaOH}) \quad 0,1 \mathrm{~N}$, usando como indicador a fenolftaleína, conforme o método desenvolvido pelo Instituto Adolfo Lutz (IAL, 2008), em bureta graduada de $25 \mathrm{~mL}$, extraindo-se $5 \mathrm{~g}$ de polpa e transferindo-as para um erlenmeyer de $200 \mathrm{~mL}$ com $50 \mathrm{~mL}$ de água destilada. Depois de determinado os valores de ST e AT, a relação ST/AT foi obtida por meio do quociente entre estas duas variáveis.

O teor de ácido ascórbico foi obtido por meio do método amido-iodo, em um erlenmeyer de 100 $\mathrm{mL}$ foi pesado $10 \mathrm{~g}$ da polpa do fruto e em seguida foi adicionado $50 \mathrm{~mL}$ de água destilada. A amostra foi homogeneizada, posteriormente foi adicionado $2 \mathrm{~mL}$ da solução previamente preparada de ácido sulfúrico (H2SO4 -2N), $1 \mathrm{~mL}$ de iodeto de potássio ( $\mathrm{KI}-10 \%)$ e $1 \mathrm{~mL}$ da solução de amido a $10 \%$, a amostra foi homogeneizada novamente. Em seguida em uma bureta graduada de $25 \mathrm{~mL}$ a amostra foi titulada com iodato de potássio ( $\mathrm{KIO} 3-0,01 \mathrm{~N})$ até o ponto de viragem, quando a amostra começou a adquirir coloração marrom. Os resultados foram expressos em mg 100g-1 (IAL, 2008).

Os carotenoides totais presentes nos frutos de $B$. crassifólia (L.) Rich nativos de Alagoas foram quantificados segundo a metodologia da AOAC (1995). Pesou-se $5 g$ da polpa do fruto em um tubo de centrifuga envolto de papel alumínio, adicionandose em seguida $15 \mathrm{~mL}$ de álcool isopropílico e $5 \mathrm{~mL}$ de hexano, a amostra foi agitada durante 2 minutos em um homogeneizador. Após a agitação, o conteúdo foi transferido para um funil de separação de $125 \mathrm{~mL}$ envolto em papel alumínio, onde se completou o volume com água destilada e amostra ficou descansando por 30 minutos, em seguida fez-se a lavagem (retirando a fase aquosa e deixando a fase de cor amarela). Após três descansos de 30 minutos cada, a amostra foi filtrada em um algodão (pulverizado com uma pitada de sulfato de sódio anidro P. A.) para um balão volumétrico de $25 \mathrm{~mL}$ envolto em papel alumínio, lavando o algodão 
com hexano e pressionando-o no funil, para retirar todo o pigmento presente no algodão. Logo após a filtragem adicionou-se a amostra $2,5 \mathrm{~mL}$ de acetona e completou-se 0 volume restante com hexano. Foi utilizado com branco solução de $5 \mathrm{~mL}$ de acetona e $45 \mathrm{~mL}$ de hexano, e as leituras foram realizadas em espectrofotômetro no comprimento de onda de $450 \mathrm{~nm}$. 0 cálculo de carotenoides totais foi realizado por meio da fórmula descrita abaixo:

Carotenoides totais $(\mathrm{mg} \%)=\frac{\mathrm{ABS} \times 100}{250 \times 1 \times \text { Peso/diluição }}$ Onde,

ABS: absorbância obtida das amostras;

Peso: peso da quantidade de polpa utilizada na análise; Diluição: diluição final do extrato de carotenoides.

As antocianinas totais e os flavonoides totais foram determinados segundo a metodologia desenvolvida por Francis (1982). Onde se pesou 1 $\mathrm{g}$ de polpa do fruto em um Becker envolto de papel alumínio, em seguida, adicionou-se $30 \mathrm{~mL}$ da solução extratora etanol $(95 \%)-\mathrm{HCl}(1,5 \mathrm{~N})$ na proporção $85: 15$, previamente preparada. As amostras foram homogeneizadas em um homogeneizador de tecidos tipo "Turrax" por 2 minutos na velocidade " 5 ". Logo após, o conteúdo foi transferido para um balão volumétrico de $50 \mathrm{~mL}$ (sem filtrar) ao abrigo da luz, aferido com a solução extratora, homogeneizado e armazenado em frasco âmbar, o qual ficou em repouso por uma noite na geladeira. No dia seguinte, o material foi filtrado em um kitassato de $100 \mathrm{~mL}$, acoplado a uma bomba de vácuo protegido da luz. As leituras foram realizadas em espectrofotômetro, no comprimento de onda de 535 $\mathrm{nm}$ para antocianinas e $374 \mathrm{~nm}$ para flavonoides. Os teores de antocianinas totais e flavonoides totais foram obtidos por meio da fórmula: absorbância $\mathrm{x}$ fator de diluição/98,2, sendo os resultados foram expressos em

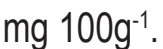

As substancias pécticas totais foram extraídas de $5 \mathrm{~g}$ de polpa e homogeneizadas em $25 \mathrm{~mL}$ de etanol $95 \%$, segundo metodologia desenvolvida por McCread e MacComb (1952). Após repouso de 30 minutos em geladeira, a amostra foi filtrada em um kitassato de 100 $\mathrm{mL}$, acoplado a uma bomba de vácuo, o resíduo foi lavado duas vezes com etanol a $75 \%$. Em seguida, o resíduo foi transferido para um becker de $50 \mathrm{~mL}$, onde se adicionou $40 \mathrm{~mL}$ de água destilada, homogeneizando a amostra. Logo após, ajustou-se o pH da amostra para 11,5 com solução de $\mathrm{NaOH} 1 \mathrm{~N}$ para posterior repouso por 30 minutos, novamente em geladeira. A seguir 0 $\mathrm{pH}$ foi ajustado para 5,5 com ácido acético glacial, para propiciar condições ideais de reação na amostra, após a inoculação de pectinase de Aspergillus niger v. Tiegem. As leituras foram feitas em espectrofotômetro, a $520 \mathrm{~nm}$, sendo os resultados expressos em \% de pectina presente na massa fresca da polpa do fruto.

As substâncias pécticas solúveis foram extraídas de $5 \mathrm{~g}$ de polpa, e homogeneizadas em 25 $\mathrm{mL}$ de etanol $95 \%$, segundo metodologia desenvolvida por McCread e MacComb (1952). Após repouso de 30 minutos em geladeira, a amostra foi filtrada em um kitassato de $100 \mathrm{~mL}$, acoplado a uma bomba de vácuo, o resíduo foi lavado duas vezes com etanol a $75 \%$. Em seguida o resíduo foi transferido para um erlenmeyer de $100 \mathrm{~mL}$, adicionando-se $40 \mathrm{~mL}$ de água destilada, a amostra foi agitada por 1 hora. Logo após, o material foi filtrado a vácuo e o sobrenadante diluído para 100 $\mathrm{mL}$ em balão volumétrico. As leituras foram feitas em espectrofotômetro, a $520 \mathrm{~nm}$, sendo os resultados expressos em \% de pectina presente na massa fresca da polpa do fruto.

\section{Análise estatística}

Foi aplicada estatística descritiva, obtendo-se os valores máximos, mínimos e médios, o erro padrão da média e o coeficiente de variação. Todas as análises foram realizadas com auxílio do software GENES (CRUZ, 2006).

\section{RESULTADOS E DISCUSSÃO}

Os frutos de B. crassifólia (L.) Rich. apresentam coloração amarela intensa quando maduros, exalando um aroma peculiar, semelhante a queijo rançoso, de sabor exótico e agradável. Consistem em drupas, com mesocarpo fino e carnoso, de casca lisa e polpa suculenta. As caraterísticas físicas dos frutos, relacionadas à aparência externa, tamanho, forma e cor da casca, e os caracteres físico-químicos relacionados ao sabor, odor, textura e composição nutricional, são parâmetros de qualidade importantes para aceitabilidade do produto pelo consumidor, seja no mercado de frutas frescas quanto no mercado de frutas processadas (Lira-Júnior, et al., 2005). 
Na Tabela 1 podem-se observar os resultados dos parâmetros físicos dos frutos de muricizeiro procedentes dos tabuleiros costeiros alagoanos. Os frutos apresentaram peso médio (MMF) de 2,72 $\pm 0,58$ $\mathrm{g}$, com amplitude de 2,07 g a 3,20 g. Com relação ao peso das sementes (MMF), verifica-se que os valores oscilaram de $0,55 \mathrm{~g}$ a 1,05 g, com média geral de 0,83 $\pm 0,38 \mathrm{~g}$. Resultados inferiores foram obtidos por Araújo et al. (2009) em frutos de B. verbascifolia de uma área de tabuleiro costeiro de Maceió - Alagoas, com peso médio de frutos e sementes de $1,21 \pm 0,01 \mathrm{~g} \mathrm{e} \mathrm{0,98}$ $\pm 0,01 \mathrm{~g}$, respectivamente. 0 diâmetro médio das sementes foi de 2,09 $\pm 0,59 \mathrm{~mm}$, com variação de 0,90 $\mathrm{mm}$ a $5,65 \mathrm{~mm}$. Na caracterização física de seis clones de muricizeiro do Banco de Germoplasma da Amazônia Oriental realizada por Souza et al. (2010), foram obtidos diâmetros médios variando de $0,75 \pm 0,07 \mathrm{~mm}$ a 0,88 \pm $0,06 \mathrm{~mm}$, valores bem próximos aos verificados nesta pesquisa. Verifica-se também que o peso dos frutos, peso das sementes e diâmetro das sementes foram bastante variável, com coeficientes de variação de $12,77 \%, 18,35 \%$ e $9,94 \%$, respectivamente.

Tabela 1. Valores médios, máximos, mínimos e desvio padrão da biometria de frutos de murici (Byrsonima crassifolia (L.) Rich.) nativos dos tabuleiros costeiros de Alagoas.

\begin{tabular}{lcccc}
\hline \multicolumn{1}{c}{ Características Biométricas } & Máximo & Mínimo & Média $\pm \mathrm{DP}$ & $\mathrm{CV}(\%)$ \\
\hline Fruto $(\mathrm{g})(\mathrm{MMF})$ & 3,20 & 2,07 & $2,72 \pm 0,58$ & 12,77 \\
Semente (g) (MMF) & 1,05 & 0,55 & $0,83 \pm 0,38$ & 18,35 \\
Fruto (mm) (DL) & 14,47 & 12,27 & $13,51 \pm 0,77$ & 4,44 \\
Fruto (mm) (DT) & 18,12 & 15,27 & $16,82 \pm 0,93$ & 5,20 \\
Diâmetro da Semente (mm) & 5,65 & 0,90 & $2,09 \pm 0,59$ & 9,94 \\
Relação DL/DT & 0,85 & 0,76 & $0,80 \pm 0,14$ & 3,44 \\
Textura (N) & 4,76 & 1,60 & $3,09 \pm 1,00$ & 33,25 \\
\hline
\end{tabular}

*MMF: média da massa fresca; DL: diâmetro longitudinal; DT: diâmetro transversal.

As variáveis de peso, tamanho dos frutos e sementes observados neste trabalho diferiram dos resultados encontrados pelos autores citados anteriormente, no entanto, estas variações estão associadas às características ambientais dos locais onde a espécie ocorre, bem como das características genéticas das matrizes. Plantas sob diferentes condições nutricionais, de temperatura, disponibilidade hídrica e agentes dispersores, sofrem uma seleção natural nestes ambientes, favorecendo o desenvolvimento de indivíduos geneticamente adaptados, que apresentam características fenotípicas peculiares que os fazem diferirem de outros indivíduos pertencentes à mesma espécie (Machado et al., 2016; Morzelle et al., 2015).

Os diâmetros longitudinais (DL) dos frutos apresentaram amplitude de variação de $12,27 \mathrm{~mm}$ a $14,47 \mathrm{~mm}$, com ponto médio de $13,51 \pm 0,77$. Já os diâmetros transversais (DT) oscilaram de $15,27 \mathrm{~mm}$ a 18,12 $\mathrm{mm}$, com média de 16,82 $\pm 0,93 \mathrm{~mm}$. No estudo da biometria de frutos de $B$. vesbascifolia (L.) Rich. oriundos de Montes Claros/MG realizado por Gusmão et al. (2006), foram verificados comprimento e diâmetro médio de 10,08 \pm 0,14 mm e 11,93 \pm 0,17 $\mathrm{mm}$, respetivamente. Araújo et al. (2009), obtiveram diâmetro longitudinal de 8,50 $\pm 0,10 \mathrm{~mm}$ (milímetro) e diâmetro transversal de 7,38 $\pm 0,11 \mathrm{~mm}$ (milímetro) em frutos de $B$. vesbascifolia (L.) Rich. nativos de Alagoas. Os valores descritos no presente estudo são superiores aos resultados obtidos pelos autores supracitados.

A relação entre o diâmetro longitudinal e transversal dos frutos é um parâmetro utilizado como indicativo do formato dos mesmos, se a relação DL/ DT for $\leq 1$ indica frutos de formato oblongo, levemente achatado, ou seja o DL é menor que o DT (Silva et al., 2016). Neste estudo foi observado relação DL/DT com amplitude de 0,76 a 0,85, e média geral de 0,80 $\pm 0,14$, indicando que os frutos de muricizeiro são levemente achatados, com formato oblongo. O conhecimento do formato dos frutos é muito importante para o manuseio pós-colheita, principalmente para frutos destinados ao processamento agroindustrial, onde 0 aspecto visual do produto final influencia o nível de aceitabilidade destes pelo consumidor, a exemplo de frutos glaceados e cristalizados, além do mais as indústrias de processamento dão preferência a frutos arredondados, por facilitar as etapas de limpeza e processamento durante 0 manuseio dos alimentos (Chitarra \& Chitarra, 2005). 
A firmeza de polpa média observada foi de 3,09 $\pm 1,00 \mathrm{~N}$, com valor mínimo de $1,60 \mathrm{~N}$ e máximo de 4,76 N. A firmeza é uma característica de qualidade relacionada à maturação dos frutos, sendo que à medida que avança o processo de maturação dos mesmos eles tendem a ficar menos firmes, e consequentemente, reduzindo sua vida útil pós-colheita. Esta característica tem sido atribuída à presença de substancias péctica, presente nas paredes celulares dos vegetais, que durante 0 amadurecimento dos frutos elas tornam-se solúveis, sendo responsáveis pelo amaciamento da polpa. Além disto, a determinação da firmeza de polpa nos dar um indicativo da resistência dos frutos ao transporte e manuseio (Schwartz et al., 2010).

Observa-se que os frutos avaliados neste estudo apresentaram variabilidade significativa quanto à firmeza da polpa, com coeficiente de variação de $33,25 \%$. A firmeza da polpa do fruto é influenciada por diversos fatores, dentre eles as características genéticas da planta, das variações climáticas regionais, com a posição do fruto na planta, com 0 grau de maturação e com o tamanho do fruto, o que pode explicar as variações observadas nesta pesquisa (Chitarra \& Alves, 2001).

$\mathrm{Na}$ Tabela 2 encontram-se os resultados físicoquímicos dos frutos de $B$. crassifólia nativos de Alagoas caracterizados neste estudo. Os frutos apresentaram altos teores de sólidos totais (ST), com concentração variando de $14,80^{\circ}$ Brix a $21,00^{\circ}$ Brix, e média geral de $17,32 \pm 1,46^{\circ}$ Brix. Carvalho et al. (2016), avaliando as características físico-químicas de frutos $B$. verbascifolia (L.) Rich. do Banco de Germoplasma da Amazônia Oriental, observaram teores oscilando de 12,20 \pm $0,35^{\circ}$ Brix a $17,72 \pm 0,55^{\circ}$ Brix. Montenegro et al. (2017), realizaram a caracterização físico-química de frutas da região amazônica, e verificaram teor médio de sólidos totais em frutos de muricizeiro de $4,20 \pm 0,01^{\circ}$ Brix. Observa-se que os frutos de murici dos tabuleiros costeiros alagoanos apresentaram teores superiores aos constatados em frutos de outras regiões do Brasil.

Tabela 2. Valores médios, máximos, mínimos e desvio padrão das análises físico-químicas dos frutos de murici (Byrsonima crassifolia (L.) Rich.) nativos dos tabuleiros costeiros de Alagoas.

\begin{tabular}{|c|c|c|c|c|}
\hline Características Físico-químicas & Máximo & Mínimo & Média \pm EP & $\mathrm{CV}(\%)$ \\
\hline ST ( ${ }^{\circ} B$ Brix) & 21,00 & 14,80 & $17,32 \pm 1,46$ & 12,29 \\
\hline AT (\%) & 2,50 & 2,39 & $2,44 \pm 0,20$ & 1,70 \\
\hline Relação ST/AT & 8,40 & 6,16 & $7,08 \pm 0,80$ & 11,36 \\
\hline $\mathrm{pH}\left(^{*}\right)$ & 3,38 & 3,33 & $3,35 \pm 0,10$ & 0,48 \\
\hline Ácido ascórbico (mg.100g-1) & 68,64 & 26,40 & $42,24 \pm 3,76$ & 33,54 \\
\hline Antocianinas $\left(\mathrm{mg} .100 \mathrm{~g}^{-1}\right)$ & 3,61 & 2,95 & $3,29 \pm 0,10$ & 7,19 \\
\hline Flavonoides $\left(\mathrm{mg} \cdot 100 \mathrm{~g}^{-1}\right)$ & 7,23 & 6,56 & $6,77 \pm 0,11$ & 3,94 \\
\hline Carotenoides (mg\%) & 1,74 & 1,43 & $1,64 \pm 0,05$ & 7,29 \\
\hline Pectina total $(\%)$ & 0,48 & 0,44 & $0,46 \pm 0,01$ & 4,66 \\
\hline Pectina solúvel (\%) & 3,26 & 3,13 & $3,20 \pm 0,02$ & 1,47 \\
\hline
\end{tabular}

* pH: potencial hidrogênionico.

O conhecimento do teor de sólidos totais é comumente utilizado como indicativo do grau de maturação para algumas espécies frutíferas. Sendo sua quantificação importante em frutos, tanto para 0 consumo in natura quanto para o processamento, tendo em vista que os consumidores dão preferência a frutos mais adocicados e menos ácidos, e nas indústrias de alimentos elevados teores destes compostos na polpa do fruto importam na menor adição de açúcares, menor tempo de evaporação da água, menor gasto de energia e elevado rendimento do produto final, proporcionando economia de tempo e recursos durante o processamento (Silva et al., 2002).
Foram observados valores de acidez total (AT) oscilando de 2,39 \% a 2,50 \%, com média de $2,44 \pm 0,20 \%$, equivalente a ácido cítrico. Costa et al. (2012), verificaram em frutos de B. crassifólia do litoral maranhense, valores de acidez total variando de 0,95 $\%$ a $1,08 \%$. Na caracterização de frutos de muricizeiro (B. crassifólia (L.) Rich.) da coleção de germoplasma da Embrapa Amazônia Oriental realizada por Carvalho et al. (2008), foi encontrada acidez total média de 2,36 $\%$ equivalente a ácido cítrico, teores semelhantes aos relatados neste estudo. 
A relação ST/AT média foi $7,08 \pm 0,80$, com um máximo de 8,40 e um mínimo de 6,16. Verificase variabilidade considerável para esta caraterística, uma vez que, o coeficiente de variação foi de $11,36 \%$. Este parâmetro é normalmente utilizado na avaliação do sabor em frutos, bem como do ponto de maturação dos mesmos, sendo mais representativo do que a medição isolada de ácidos e açucares, dando a ideia da predominância do sabor ácido ou doce na polpa do fruto, ou ainda se há equilíbrio entre eles, sendo que para o mercado de frutas frescas e/ou processadas alta relação ST/AT é mais desejável, portanto os frutos de muricizeiro seriam indicados tanto para o consumo in natura quanto para o processamento (Dias et al., 2011).

Com relação ao $\mathrm{pH}$, os frutos apresentaram-se ácidos, contudo não foi observada grandes amplitudes de variação, oscilando de 3,33 a 3,38, com média de $3,35 \pm 0,1$. Estes valores de $\mathrm{pH}$ estão acima do recomendado pelo Ministério da Agricultura, Pecuária e Abastecimento (MAPA, 2016) para polpa de murici (B. crassifólia (L.) Rich.) que é de 2,80. Porém, se comparando com outros frutos da família Malphigaceae, o pH encontra-se dentro da normalidade, por exemplo, em frutos de $B$. verbascifolia (L.) Rich. e B. myricifolia Griseb. de 3,24 a 3,60, respectivamente (Guimarães et al., 2008; Vallilo et al., 2007). Dias et al. (2011), afirmam que para frutos destinados ao processamento valores de $\mathrm{pH}$ baixos favorecem a conservação do produto, não carecendo a adição de aditivos (ácidos) para evitar a proliferação de microrganismos, e que valores mais altos são preferíveis para o consumo in natura dos frutos.

Os frutos de muricizeiro podem ser considerados como boa fonte de vitamina $\mathrm{C}$, uma vez que, a Legislação Brasileira (BRASIL, 2005) recomenda a ingestão diária deste composto químico em torno de $60 \mathrm{mg}$ para adultos. Observa-se que os teores variaram de $26,40 \mathrm{mg} .100 \mathrm{~g}-1$ a $68,64 \mathrm{mg} .100 \mathrm{~g}-1$, a média geral obtida foi de $42,24 \pm 3,76 \mathrm{mg} \cdot 100 \mathrm{~g}-1$. $\mathrm{Na}$ caracterização físico-química de frutos da Amazônia realizada por Canuto et al. (2010), foi verificado teor médio de vitamina $C$ em frutos de murici de 0,30 \pm $0,1 \mathrm{mg} .100 \mathrm{~g}-1$, teor semelhante ao constatado neste estudo. $O$ teor de vitamina $C$ foi bastante variável na polpa dos frutos, tendo em vista que o coeficiente de variação foi de $33,54 \%$.

As antocianinas, os flavonoides e os carotenoides são compostos químicos sintetizados a partir do metabolismo secundário dos vegetais, que são responsáveis por conferir a folhas, flores e frutos as variadas tonalidades que vão do vermelho ao roxo e do amarelo ao alaranjado, sendo muito utilizados nas indústrias alimentícias como corantes naturais. Além disto, eles atuam na prevenção contra auto-oxidação e peroxidação de lipídeos em sistemas biológicos, prevenindo elou reduzindo diversas doenças crônicas não transmissíveis como o câncer, doenças cardiovasculares, derrames, entre outras, por meio da atividade antioxidante desenvolvida (Pereira et al., 2017).

Os frutos de muricizeiro são boa fonte de compostos bioativos, a concentração média de antocianinas totais foi de $3,29 \pm 0,10 \mathrm{mg}$. $100 \mathrm{~g}-1$, com teores variando de $2,95 \mathrm{mg} .100 \mathrm{~g}-1$ a $3,61 \mathrm{mg} .100 \mathrm{~g}-1$ (grama). Devido os frutos de murici ser de coloração amarela o teor de flavonoide totais foi superior ao de antocianinas, com concentração variando de 6,56 mg.100g-1 a 7,23 mg.100g-1, com média geral de $6,77 \pm 0,11 \mathrm{mg} \cdot 100 \mathrm{~g}-1$. Vale ressaltar que 0 teor destes compostos em frutos é muito variável, onde as discrepâncias observadas podem ser oriundas de diversos fatores, como época da colheita dos frutos, características genéticas da planta, fotoperíodo, temperatura, disponibilidade hídrica, condições nutricionais, dentre outros (Pereira et al., 2017).

Para um alimento ser referido como boa fonte de carotenoides ele deve possuir no mínimo

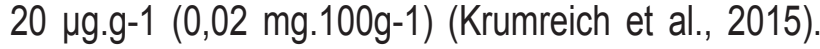
Com relação aos carotenoides totais em frutos de muricizeiro, verifica-se que o teor médio encontrado foi $1,64 \pm 0,05 \mathrm{mg} \cdot 100 \mathrm{~g}-1$, oscilando de 1,43 mg.100g-1 a $1,74 \mathrm{mg} .100 \mathrm{~g}-1$. Desta forma, os frutos de $B$. crassifólia podem ser considerados como boa fonte, tendo em vista que os valores constatados neste estudo foram superiores ao referenciado na literatura.

Quanto ao teor de pectinas, os frutos apresentaram teores consideráveis, sendo em sua maioria pectina solúvel. 0 teor médio de pectina total foi de $0,46 \pm 0,01 \%$, variando de $0,44 \%$ a $0,48 \%$. Já a porcentagem média de pectina solúvel foi de 3,20 \pm $0,02 \%$, oscilando de $3,13 \%$ a 3,26\%. Os dados obtidos mostram o potencial de utilização dos frutos muricizeiro nativos de Alagoas nas indústrias de processamento de alimentos, na elaboração de geleias, sucos, doces, compotas, sorvetes, entre outras. Em frutos de $B$. verbascifolia (L.) Rich. provenientes do cerrado 
brasileiro foram detectados teores de pectina total e de pectina solúvel superiores aos obtidos neste estudo, com valores de $746,81 \pm 58,05 \mathrm{mg} .100 \mathrm{~g}-1$ e $72,18 \pm 1,33$ mg.100g-1, respectivamente (Morzelle et al., 2015).

As variações observadas quanto aos parâmetros físicos e físico-químicos dos frutos de muricizeiro nativos de Alagoas, demostram que a espécie apresenta alto potencial genético para futuros trabalhos de domesticação e melhoramento. Além do mais, os frutos possuem características atraentes para o mercado de frutas frescas e processadas, como também teores consideráveis de compostos químicos com propriedades biologicamente funcionais, o que possibilita a entrada destes a novos nichos de mercado, como alimento diferenciado.

Osfrutos de muricizeiro possuem características físicas e físico-químicas atrativas tanto para o mercado de frutas frescas como para o de frutas processadas, destacando-se por possuir alto conteúdo de sólidos totais e baixa acidez, teor considerável de vitamina $C$, e também por ser rico em compostos bioativos. Os resultados apontam um grande potencial da espécie, podendo subsidiar futuros trabalhos de seleção de matrizes promissoras, domesticação e melhoramento genético da espécie.

\section{AGRADECIMENTOS}

À Universidade Federal de Alagoas - UFAL e ao Laboratório de Pós-colheita de Frutos do Centro de Ciências Agrárias da Universidade Federal de Alagoas - CECA/UFAL, pelo suporte físico e cientifico necessários para a realização deste estudo.

\section{REFERÊNCIAS BIBLIOGRÁFICAS}

Araújo, R. R.; Santos, E. D.; Lemos, E. E. P.; Alves, R. E. Caracterização Biométrica de Frutos e Sementes de Genótipos de Murici (Byrsonima verbascifolia (L.) Rich.) do Tabuleiro Costeiro de Alagoas. Revista Caatinga, 2009, 22, 3, 220-224.

AOAC - Association of official analytical chemists international. Official Methods of Analysis. 16 ed. Arlington, 1995, 2, 474p.

Blind, A. D.; Serudo, R. N.; Miranda, C.; Figueiredo, J. N. R.; Silva-Filho, D. F.; Noda, H. Biometria em Frutos e
Sementes de Mapati (Pourouma cecropiifolia). Nucleus, 2016, 13, 1, $6 \mathrm{p}$.

Belisário, C. M.; Coneglian, R. C. C. Qualidade de Frutos de Murici (Byrsonima crassifólia, Malpighiaceae) Armazenados sob Refrigeração. Global Science and Technology, 2013, 6, 2, 95-101.

BRASIL. Agência Nacional de Vigilância Sanitária. Resolução RDC n² 269, de 22 de setembro de 2005. Aprova o "Regulamento Técnico sobre a Ingestão Diária Recomendada de Proteínas, Vitaminas e Minerais". D. 0. U. - Diário Oficial da União. ANVISA - Agência Nacional de Vigilância Sanitária, de 23 de setembro de 2005.

Carvalho, A. V.; Nascimento, W. M. O. Caracterização Físico-química e Química da Polpa de Frutos de Murici. Belém, PA: Embrapa Amazônia Oriental, 2016. 17 p. - (Boletim de Pesquisa e Desenvolvimento/Embrapa Amazônia Oriental, 106).

CETAP - Centro Ecológico, Rede Ecovida de Agroecologia e Terra do Futuro. Frutas Nativas: alimentos locais, sabores e ingredientes especiais, 2016, Passo Fundo/RS, 22 p.

Costa, T. F.; Mendes-Filho, N. E.; Teles, A. M.; Marinho, S. C.; Mouchreck - Filho, V. E.; Nascimento, A. R. Composição Nutricional do Murici Espécie Crassifólia Originária do Litoral Maranhense. In: $64^{\mathrm{a}}$ Reunião Anual da SBPC, 2012, São Luís - MA, 1 p.

Canuto, J. A. B.; Xavier, A. A. O.; Neves, L. C.; Benassi, M. T. Caraterização Físico-química de Polpas de Frutos da Amazônia e sua Correlação com a Atividade AntiRadical Livre. Revista Brasileira de Fruticultura, 2010, 32, 4, 1196-1205.

Carvalho, J. E. U.; Vasconcelos, M. A. M.; Nascimento, W. M. O.; Gonçalves, A. C. S. Caracterização dos cachos e dos frutos de dois acessos promissores de muricizeiro. In: II Simpósio Brasileiro de Recursos Genéticos, 2008, Águas Claras - DF, 1 p.

Cruz, C.D. Programa GENES: análise multivariada e simulação. Viçosa: UFV, 2006 175p.

Chitarra, M. I. F.; Chitarra, A. B. Pós-colheita de frutos e hortaliças: fisiologia e manuseio, 2005, Lavras: UFLA, 795p. 
Chitarra, A. B.; Alves, R. E. Tecnologia Pós-colheita para Frutas Tropicais. Fortaleza: Instituto de Desenvolvimento da Fruticultura e Agroindústria FRUTAL/ Sindicato dos Produtores de Frutas do Estado do Ceará, 2001, 436 p.

Dias, A. B.; Carvalho, M. A. P.; Dantas, A. C. V. L.; Fonseca, V. J. A. Variabilidade e Caracterização de Frutos de Pitangueiras em Municípios Baianos. Revista Brasileira de Fruticultura, 2011, 33, 4, 1169-1177.

FLORA DO BRASIL 2020 em construção. Jardim Botânico do Rio de Janeiro. Disponível em: <http:// reflora.jbrj.gov.br/reflora/floradobrasil/FB19419>. Acesso em: 25 Jul. 2018.

Francis, F.J. Analysis of anthocyanins. In: MARKAKIS, P. (ed.). Anthocyanins as food colors. New York: Academic Press, 1982, 181-207.

Guimarães, M. M.; Silva, M. S. Valor nutricional e características físicas e químicas de frutos de muricipassa (Byrsonima verbascifolia). Ciência e Tecnologia de Alimentos, 2008, 28, 4, 817-821.

Gusmão, E.; Vieira, F. A.; Fonseca-Júnior, E. M. Biometria de Frutos e Endocarpos de Murici (Byrsonima verbascifolia Rich. ex A. Juss.). Revista Cerne, 2006, $12,1,84-91$.

IAL - Instituto Adolfo Lutz. Métodos Físico-químicos para Análise de Alimentos. $4^{a}$ ed., 2008, v. 1, 1020 p.

Krumreich, F. D.; Corrêa, A. P. A.; Silva, S. D. S.; Zambiazi, R. C. Composição Físico-química e de Compostos Bioativos em Frutos de Bromelia antiacantha Bertol. Revista Brasileira de Fruticultura, 2015, 37, 2, 450-456.

Lira-Júnior, J. S.; Musser, R. S.; Melo, E. A.; Maciel. M. I. S.; Lederman, I. E.,; Santos, V. F. Caracterização Física e Físico-química de Frutos de Cajá-Umbu (Spondias spp.). Ciência e Tecnologia de Alimentos, 2005, 25, 4, 757-761.

Montenegro, J.; Aniceto, A.; Abreu, J. P.; Teodoro, A. J. Características Físico-químicas e Atividade Antioxidante de Frutas da Região Amazônica. In: 69ª Reunião Anual da SBPC, 2017, Belo Horizonte - MG, 4 p.
Machado, C. G.; Oliveira, S. S. C.; Cruz, S. C. S.; Mendonça, N. G. Biometria e Caraterização Morfológica de Sementes de Araticum Oriundas de Matrizes de Palminópolis - GO. Global Science and Technology, 2016, 9, 1, 41-47.

BRASIL. Ministério da Agricultura Pecuária e Abastecimento. Portaria $n^{0}$ 94, de 30 de Agosto de 2016. Aprova o "Projeto de Instrução Normativa e Anexo que visam estabelecer em todo território nacional a complementação dos padrões de identidade e qualidade de polpa de fruta". D. O. U. - Diário Oficial da União DOU de 01/09/2016 (nº 169, Seção 1, pág. 2).

Mozelle, M. C.; Bachiega, P.; Souza, E. C.; VilasBoas, E. V. B.; Lamounier, M. L. Caracterização Física e Química de Frutos de Curriola, Gabiroba e Murici Proveniente do Cerrado Brasileiro. Revista Brasileira de Fruticultura, 2015, 37, 1, 096-103.

McCread, P. M,; McComb, E. A.; Extraction end determination of total pectin materials. Analytical Chemistry, 1952, 24, 12, 1586-1588.

Pereira, E. S.; Ribeiro, J. A.; Raphaelli, C. O.; Camargo, T. M.; Araújo, V. F.; Franzon, R.; Vizzotto, M. Compostos bioativos e potencial antioxidante de genótipos de araçá avaliados em dois ciclos produtivos. Revista da 14ª Jornada de Pós-graduação e Pesquisa, 2017, 11 p.

Rocha, M. S.; Figueiredor. W.; Araújo, M. A. M.; Moreira-Araújo, R. S. R. Caracterização Físico-química e Atividade Antioxidante (in vitro) de Frutos do Cerrado Piauiense. Revista Brasileira de Fruticultura, 2013, 35, 4, 933-941.

Silva, Q. J.; Figueiredo, F. J.; Lima, V. L. A. G.; Características físicas e químicas de cirigueleiras cultivadas na Zona da Mata Norte de Pernambuco. Revista Ceres, 2016, 63, 3, 285-290.

Silva, M. I.; Martins, J. N.; Alves, J. E. A.; Costa, F. F. P. Caraterização físico-química da polpa de umbu em camada de espuma. Revista Semiárido De Visu, 2015, 3, 2, 82-91.

SEMARH-AL. Município de Maceió. Boletim Dezembro - 2015. Secretaria de Estado do Meio Ambiente e dos Recursos Hídricos. Maceió, AL. Janeiro, 2015. 
Schwartz, E.; FachinelO, J. C.; Barbieri, R. L.; Silva, J. B. Avaliações de Populações Butia capitata de Santa Vitório do Palmar. Revista Brasileira de Fruticultura, 2010, 32, 3, 736-745.

Souza, C. B. L.; Nascimento, W. M. O.; Carvalho, J. E. U. Caraterização Física de Frutos de Seis Clones de Muricizeiro. In: $14^{\circ}$ Seminário de Iniciação Científica da EMBRAPA, 2010, Embrapa Amazônia Oriental, Belém - Pará, 4 p.

Silva, J.; Silva, E. S.; Lima \& Silva, P. S. Determinação da Qualidade e do teor de Sólidos Solúveis nas Diferentes Partes do Fruto da Pinheira (Annona squamosa L.). Revista Brasileira de Fruticultura, 2002, 24, 2, 562-564.
Valillo, M. I.; Pastore, J. A.; Eston, M. R.; Garbelotti, M. L.; Oliveira, E. Caracterização Química e Valor Nutricional dos Frutos de Byrsonima myricifolia Griseb Malpighiaceae - Alimentos de Aves Silvestres. Revista Instituto Floresta, 2007, 19, 1, 39-45.

Zuffo, A. M.; Andrade, F. R.; Zuffo-Júnior, J. M. Caracterização Biométrica de Frutos e Sementes de Baru (Dipteryx alata Vog.) na Região Leste de Mato Grosso, Brasil. Revista de Ciências Agrárias, 2014, 37, 4, 463-471. 